\title{
The Role of Colony Temperature in the Entrainment of Circadian Rhythms of Honey Bee Foragers
}

\author{
Authors: \\ Manuel A. Giannoni-Guzmán¹, Emmanuel Rivera², Janpierre Aleman-Rios³, Alexander M. \\ Melendez Moreno ${ }^{3}$, Melina Perez Ramos², Eddie Pérez-Claudio ${ }^{4}$, Darimar Loubriel${ }^{1}$, Darrell \\ Moore $^{5}$, Tugrul Giray ${ }^{3}$ and Jose L. Agosto-Rivera ${ }^{3}$
}

\section{Affiliations:}

1. Department of Biological Sciences, Vanderbilt University, Nashville, TN, USA

2. Department of Biology, Brandeis University, Waltham, MA, USA

3. Department of Biology, University of Puerto Rico Rio Piedras Campus, San Juan, PR

4. Department of Biomedical Informatics, University of Pittsburgh, School of Medicine, Pittsburgh, PA, USA

5. Department of Biological Sciences, East Tennessee State University, Johnson City, TN, USA

Corresponding author: Manuel A. Giannoni-Guzmán

e-mail: manuel.giannoni10@gmail.com 
bioRxiv preprint doi: https://doi.org/10.1101/2020.08.17.254722; this version posted May 16, 2021. The copyright holder for this preprint (which

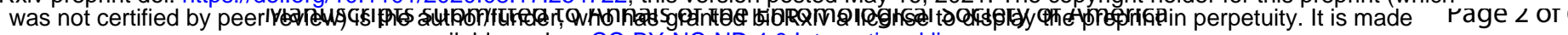
available under aCC-BY-NC-ND 4.0 International license. 


\section{Abstract}

Honey bees utilize their circadian rhythms to accurately predict the time of day. This ability

3 allows foragers to remember the specific timing of food availability and its location for several

4 days. Previous studies have provided strong evidence toward light/dark cycles being the primary

5 Zeitgeber for honey bees. Work in our laboratory described large individual variation in the

6 endogenous period length of honey bee foragers from the same colony and differences in the

7 endogenous rhythms under different constant temperatures. In this study, we further this work by

8 examining temperature inside the honey bee colony. By placing temperature and light data

9 loggers at different locations inside the colony we measured temperature at various locations

10 within the colony. We observed significant oscillations of temperature inside the hive, that show

11 seasonal patterns. We then simulated the observed temperature oscillations in the laboratory and

12 found that using the temperature cycle as a Zeitgeber, foragers present large individual

13 differences in the phase of locomotor rhythms with respect to temperature. Moreover, foragers

14 successfully synchronize their locomotor rhythms to these simulated temperature cycles.

15 Advancing the cycle by six hours, resulted in changes in the phase of activity in some foragers in

16 the assay. The results shown in this study highlight the importance of temperature as a potential

17 Zeitgeber in the field. Future studies will examine the possible functional and evolutionary role of

18 the observed phase differences of circadian rhythms.

22 Keywords: Honey bees, Foragers, circadian, Temperature, synchronization, locomotor activity 


\section{Introduction:}

One of the major functions of endogenous circadian clocks is to maintain the appropriate

27 timing (phasing) of physiological and behavioral processes with respect to daily variations (such

28 as light-dark and temperature cycles) in the external environment. Typically, most of these clock-

29 driven biological rhythms are not in perfect synchrony with such environmental cycles but, instead,

30 occur at stable, fixed phases that anticipate or trail certain aspects (dawn, dusk, increasing or

31 decreasing temperatures) of the environmental cycles(Moore and Rankin 1983, Frisch and

32 Aschoff 1987, Panda et al. 2002, Hut and Beersma 2011). The endogenous circadian clock and

33 the circadian rhythms orchestrated by it are thus entrained by daily environmental time cues

34 (Zeitgebers). While circadian rhythms were originally measured as daily behavioral patterns, such

35 as locomotor activity, egg laying, mating, and food acquisition, at the molecular level, circadian rhythms are driven by a set of proteins that generate negative feedback loops that regulate the transcription, translation and post translational modifications of a large number of canonical clock genes (Dunlap 1999, Blau 2001, Cyran et al. 2003, Gardner et al. 2006). These feedback loops generate near 24-hour (circadian) oscillations in the expression levels of the genes that make up the clock (Takahashi 1999, Ko and Takahashi 2006).

In honey bees, the circadian clock is associated with various complex behavioral

42 processes that drive the survival and fitness of the colony. Drones and queens (the reproductive

43 castes in the colony) mate at a specific time during the day (Galindo-Cardona et al. 2012).

44 Foragers, who go out in search of different resources during daylight, learn the time and location

45 of a food source and anticipate its availability on following days (von Frisch 1967, Moore 2001, 46 Moore and Doherty 2009).Foragers also rely on the circadian clock for time-compensation, an 47 essential component of their sun-compass navigation and dance language communication 48 functions (Lindauer 1960, von Frisch 1967, Cheeseman et al. 2012) Although these and other 
processes rely on precise timing of the circadian clock, few studies have examined the potential environmental cues that entrain circadian rhythms in nature.

The first studies of honey bee circadian rhythms looked at foraging rhythms at the colony

52 level (Buttel-Reepen 1900, Forel 1910, Wahl 1932, 1933). Studies examining the potential

53 Zeitgebers that entrain circadian rhythms in honey bee colonies as well as individual bees

54 concluded that light-dark cycles are the primary entraining agents (Renner 1960, Beier 1968,

55 Beier and Lindauer 1970, Detrain et al. 1999). Studies in which groups of individuals from whole

56 colonies were trained to visit a specific food source at a particular time of day were then

57 translocated to a different time zone (ex. New York to California) exhibited foraging activity at the

58 time relative to their original light-dark cycles. Over a span of several days, foragers from the

59 transplanted colony re-entrained to the new light-dark regimen (Renner 1959). At the individual

60 forager level, studies have demonstrated that light-dark cycles indeed entrain forager locomotor

61 rhythms (Spangler 1972, Moore and Rankin 1985) and that the lights-off transition determines the

62 forager's phase of activity (Moore and Rankin 1993). However, the fact that honey bee colonies

63 and individuals entrain to light-dark cycles does not exclude the possibility of entrainment by other

64 environmental cues.

An important aspect of hive maintenance is that honey bees socially regulate colony temperature, keeping it optimally at $35^{\circ} \mathrm{C}$ (Heinrich 1980). At the behavioral level this is achieved

67 by heat production via vibration of wing muscles, fanning (ventilation), and water evaporation 68 inside the colony (Seeley 1974, Kronenberg and Heller 1982). Researchers examining the 69 mechanisms underlying this thermoregulation found that individual variation at the genetic level 70 is associated with differences in worker's fanning response threshold to temperature (Jones et al.

71 2004). This variation results in different patrilines fanning at different temperatures and, therefore,

72 promoting the stability of brood nest temperature (Jones et al. 2004). A primary challenge to 73 colony thermoregulation is the daily variation in external heat associated with sunlight. The 
74 contribution of variation in circadian rhythms at the level of the individual bee to thermoregulation

75 remains unknown.

Thermoregulation of honey bee colonies is essential for colony performance and survival

77 (Heinrich , 1981; Heinrich, 1993). Experiments examining the effects of low temperatures (28-

$7830^{\circ} \mathrm{C}$ ) on brood development revealed that these temperatures can cause shriveled wings or other

79 malformations, while brood kept at high temperatures $\left(38^{\circ} \mathrm{C}-40^{\circ} \mathrm{C}\right)$ exhibit high mortality rates

80 (Heinrich, 1993; Himmer, 1927). Subsequent studies showed that pupal development at $32^{\circ} \mathrm{C}$,

81 only $3^{\circ} \mathrm{C}$ lower than optimal core temperature, results in significant deficits in waggle dance

82 behavior as well as learning and memory assays, compared to bees raised at $36^{\circ} \mathrm{C}$ (Tautz et al.

83 2003). Nonetheless, little is known about the effects of colony temperature on circadian rhythms

84 in honey bees.

While in the tropics and neotropics environmental temperatures are somewhat stable throughout the year, honey bee colonies in temperate and subpolar regions are exposed to drastic temperature changes on an annual basis. Honey bee colonies are heterothermic. In the winter, temperature regulation is driven around the survival of the cluster. When a colony is exposed to 1985). At the individual level, workers will produce heat by shivering their flight muscles in order

91 to keep the core temperature of the cluster above the environmental temperature (Heinrich and

92 Esch 1994, Stabentheiner et al. 2003). In contrast, during the spring and summer when colonies

93 are rearing brood, temperature must be controlled within a very narrow range(Kronenberg and

94 Heller 1982, Fahrenholz et al. 1989, Jones et al. 2004). Even small discrepancies from the $35^{\circ} \mathrm{C}$ 95 optimal temperature for brood development can have negative consequences for adult worker 96 fitness (Tautz et al. 2003, Jones et al. 2004). 
99 circadian locomotor rhythms of individual foragers in the laboratory (Moore and Rankin 1993).

100 However, whether temperature cycles strong enough to entrain circadian rhythms exist inside the

101 colony has not been thoroughly studied. Changes in environmental temperature in the laboratory

102 have been shown to have strong effects on the endogenous period length of foragers (Fuchikawa

103 and Shimizu 2007, Giannoni-Guzman et al. 2014). Furthermore, work from our group has

104 revealed a broad range of individual difference in the endogenous period length of the circadian

105 clock among foragers (Giannoni-Guzman et al. 2014). This large variation in the endogenous

106 period length could be adaptive at the colony level with possible effects on fanning, shivering and

107 clustering behaviors and could result in large differences in the phase of the circadian clock to 108 time givers.

The primary goal of this study was to ascertain if temperature changes on a daily basis

110 inside honey bee colonies and, if so, are these changes (temperature cycles) capable of

111 influencing circadian rhythms of honey bee foragers? We measured light and temperature at

112 various locations inside of the colony to determine if these potential Zeitgebers showed daily

113 oscillations. We then explored the effects of temperature cycles observed in the colony on the

114 circadian locomotor rhythms of honey bee foragers in the laboratory. Finally, we phase-shifted

115 the temperature cycle in an attempt to confirm if the locomotor rhythms in individual bees were

116 capable of stable entrainment to the temperature cycles.

\section{Materials and Methods}

\section{Colony Light and Temperature Measurements}

Light and temperature measurements were carried out using $\mathrm{HOBO}^{\circledR}$ pendant data

120 loggers (UA-002-64). Four loggers were placed inside the colony at the center, entrance,

121 periphery and top, while one was placed outside the hive as shown (Figure 1A). The colony in

122 which we collected these measurements was a two story colony in good health with a naturally

123 mated queen laying eggs, and containing approximately 6-8 brood frames and 60,000 workers. 
124 With the exception of 30 minutes during July 11, 2013, when data were uploaded from the

125 pendants and the batteries were replaced, temperature and light measurements were

126 continuously collected in 30-minute intervals from June 13, 2012 until September 2, 2014. The

127 bees and colonies described in our experiments were located in Gurabo, Puerto Rico. Throughout

128 the year, mean high temperatures averaged from $28-30^{\circ} \mathrm{C}$, while the low temperatures averaged

129 between $16-20^{\circ} \mathrm{C}$ (Acevedo-Gonzalez et al. 2019, Feliciano-Cardona et al. 2020). Temperature

130 and light data presented are averaged monthly values for the month of July 2013 (Figure 1). The

131 peak to trough amplitudes were calculated using the calculated amplitudes of the temperature

132 oscillations and multiplying by 2 (Figure 2). The phase of the average monthly temperature was 133 calculated using cosine fitting in the circadian dynamics app (24 Dimensions LLC).

\section{Forager Collection}

All of the bees utilized in our experiments came from colonies in good health that had naturally mated queens and were laying eggs at the time of the experiments. For each experiment, foragers were collected returning to the colony by blocking the entrance with 8-mesh wire screen and capturing them in tubes as previously described (Giray et al. 2007). Collected bees were provided with food and water during transportation to UPR Rio Piedras campus (30-40 min car ride). Once in the lab, bees were anesthetized and placed in locomotor activity monitors as

141 previously described (Giannoni-Guzman et al. 2014).

\section{Experiment 1: Simulating temperature cycles of the colony in the laboratory}

Locomotor activity recordings were performed inside an environmental chamber (Percival,

144 I-30BLL), where temperature was programed to oscillate with an amplitude of $9.2^{\circ} \mathrm{C}$, as observed

145 in the periphery of the colony (Figure 1C). To ensure that the temperature was oscillating in the 146 same manner (or as close as possible) as the observed oscillation in nature, the incubator was 147 set up and calibrated 2 weeks prior to the experiment. Age was controlled by paint marking 148 individual 1-day old workers and returning them to the colony on October $7^{\text {th }} 2014$. Foragers were 
149 from the same colony of origin. Locomotor activity recordings began at 21 days of age and took

150 place from October $28^{\text {th }}$ until November $7^{\text {th }} 2014$. Phase analysis of locomotor activity was

151 performed on days 6-11 of locomotor recording, to allow 5-6 days needed for bees to acclimate

152 to square wave temperature cycles (Moore and Rankin 1993). Data of foragers in constant

153 darkness at $35^{\circ} \mathrm{C}$ used is from previously published work (Giannoni-Guzman et al. 2014).

\section{Experiment 2: 6-hour phase advance of simulated temperature cycles}

Foragers from the same colony were collected at the entrance of the colony September $18^{\text {th }}, 2015$ on a sunny afternoon and placed in constant darkness with oscillating temperature

157 cycles later that same afternoon. Data shown and used for analysis were taken beginning the first 158 midnight. Locomotor activity assays were conducted using the same environmental conditions as 159 experiment 1 for the first 6 days of the experiment. On the $7^{\text {th }}$ day the environmental temperature cycle was advanced by 6 hours and was kept with this timing until the end of the experiment 161 (Figure 4 and 5).

\section{Data analyses}

Locomotor activity data were processed using MatLab® toolboxes developed in Jeffrey

164 Hall's laboratory (Levine et al. 2002). Period length was calculated using autocorrelation analysis.

165 The phase angle $(\psi)$ of the acrophase locomotor rhythm in relation to the acrophase temperature 166 cycles to which bees were exposed was determined via cross correlation analysis. Changes in 167 the phase of temperature measurements throughout the year were analyzed via Mixed-effect 168 Modeling and post hoc tests were performed between groups.

\section{Results}

171 for the circadian clock of honey bees under laboratory conditions (Moore and Rankin 1993).

172 However, whether temperature cycles capable of entrainment of the circadian rhythm of honey 
173 bees are present inside the colony was unknown. To examine if temperature cycles are present

174 in honey bee colonies, we placed 5 data loggers at different locations of the colony (center, 175 entrance, top, periphery and outside) and recorded light and temperature measurements in 30176 minute intervals (Figure 1A). Our results revealed that temperature oscillates inside honey bee 177 colonies in a daily manner, with amplitudes greater than 7 degrees (Figure 1). Specifically, we 178 observed that at the center of the colony temperature was maintained within $35 \pm 0.7{ }^{\circ} \mathrm{C}$, while 179 daily temperature cycles at the entrance (peak to trough amplitude $=7.3^{\circ} \mathrm{C}$ ), periphery (peak to 180 trough amplitude $=9.2^{\circ} \mathrm{C}$ ) and top $\left(\right.$ amplitude $=16.3^{\circ} \mathrm{C}$ ) of the colony were detected. The control 181 data logger that was placed outside the colony, as expected, detected strong temperature and 182 light-dark cycles with greater amplitude than those detected in the colony (Figure 1E). In addition, 183 the presence of light inside the colony was only detected by the logger at the entrance and was 184200 times less at its highest peak than that detected by the logger outside the hive (Figure 1E, $185 \mathrm{~F})$.

Having observed that temperature oscillates in parts of the colony, we next looked at

187 whether there were significant seasonal changes in these temperature oscillations inside the 188 colony. We focused on comparing the peripheral temperature (Figure 1C) with that of the outside 189 environment. Our results show that the amplitude and the phase of temperature cycles at the 190 periphery of the hive varies throughout the year. We observed significant phase and amplitude 191 differences between the periphery and environment during the spring and summer months, for 192 example May (Figure 2A), with similar phasing and amplitude of the cycles in the month of 193 December (Figure 2B). The amplitude of the temperature cycles in the periphery of the colony 194 was significantly different from the environment for all months with the exception of December 195 and January (Figure 2C). Importantly, the variance over the year was significantly less inside the 196 periphery of the hive than outside $\left(F_{(11,11)}=3.89, p=0.0334^{*}\right)$. Comparing the mean phase of the 197 two temperatures revealed significant phase delays in the peak of peripheral temperature cycles 
198 from April to July compared to those of the environment (Figure 2D). These data suggests that 199 bees inside of the colony actively regulate the phase and amplitude of temperature oscillations in 200 the periphery of the hive throughout the year.

Given the previously reported effects of constant environmental temperature on the endogenous rhythm of honey bees (Fuchikawa and Shimizu 2007, Giannoni-Guzman et al. 2014), we examined the possible effect of the observed temperature cycles on the locomotor rhythms of

204 foragers. We simulated the temperature cycle recorded from the periphery of the colony in the 205 laboratory and measured the locomotor activity rhythms of individual foragers subjected to this 206 cycle under constant dark conditions. We simulated the peripheral temperature oscillation of the 207 month in which we performed the bees were collected (October), which had a $9.2^{\circ} \mathrm{C}$ peak to 208 trough amplitude. We hypothesized that exposing foragers to simulated temperature cycles would result in their locomotor activity rhythms achieving a stable, consistent phase relationship with the temperature cycle. Alternatively, locomotor activity could still be influenced by the temperature 211 cycle but not attain a fixed phase relationship. Our results showed consistent phase relationships,

212 but with a broad range of individual differences among the phases $(\psi)$ of locomotor activity with 213 respect to the temperature cycle (Figure 3).

Most individuals in our sample were phase advanced (Figure 3A), while some showed a 215 delayed phase (Figure 3B). Phase quantification for each individual was performed via cross216 correlation of the locomotor activity and the temperature cycle (Figure 3, panel (iii)). Frequency 217 distribution of the phase of individuals revealed that more than 60 percent of foragers are phase 218 advanced to the temperature cycle (Figure 3C). In addition, the mean period \pm SE of the activity 219 rhythm under the temperature cycle was $24.00 \pm 0.06 \mathrm{~h}$ and its variance was significantly smaller 220 than that of the period of foragers under constant conditions (Giannoni-Guzman et al. 2014) (Fig. 221 3D). The 24.00 hour period of the locomotor activity rhythm under the temperature cycle, coupled 222 with the fact that the variance in period is smaller under the temperature cycle compared to 
223

224

225

226

227

228

229

230

231

232

233

234

235

236

237

constant conditions $(23.8 \pm 0.19 \mathrm{~h})($ Giannoni-Guzman et al. 2014), suggests that the locomotor activity rhythm is entrained to the temperature cycle.

To further test if the observed temperature cycles were capable of entraining the locomotor rhythms of foragers, we performed a 6-hour phase advance of the temperature cycle on the $7^{\text {th }}$ day of locomotor activity measurements (Figure 4). We hypothesized that if the temperature cycles observed in the colony were capable of entraining the circadian locomotor rhythms, then shifting the temperature cycle would result in a shift in the phase of locomotor activity of bees over several days (transients) until resuming the previous phase relationship with respect to the temperature cycle. Consistent with this hypothesis, we did observe that approximately $51 \%$ individuals showed a response to the phase advance of the temperature cycles (Figure $4 \mathrm{~A}, \mathrm{~B}$ and C). Within these individuals $56 \%$ gradually advanced their locomotor phase of activity (Figure $4 \mathrm{~A}$ B), consistent with the expression of transients associated with re-entrainment, while $44 \%$ abruptly advanced their phase with respect to the temperature cycle, which could be consistent with masking (Figure 4C). In these cases, the activity apparently moved to establish a consistent phase relationship with the new temperature cycle.

In addition to the foragers that responded to shifts in the temperature cycle, we also observed that approximately $49 \%$ of foragers were apparently unaffected by the temperature shifts (Figure 4D). Furthermore, a large subset of the foragers in this experiment exhibited shortperiod activity rhythms and no discernable response to the temperature advance (Figure 5A). To determine if the magnitude of the shift correlated with the phase prior to the temperature advance, we calculated the magnitude of phase changes using the following formula: ((Phase after temperature advance - Phase before temperature advance)/6) $\times 100$. This correlation revealed that the later the peak of activity prior to the shift the greater the phase change (Figure 5B). However, a correlation of the magnitude of phase change and period length before the shift was positive (Figure $5 \mathrm{C})$, suggesting changes in phase are mostly driven by changes in the period length of the foragers 
bioRxiv preprint doi: https://doi.org/10.1101/2020.08.17.254722; this version posted May 16, 2021. The copyright holder for this preprint (which

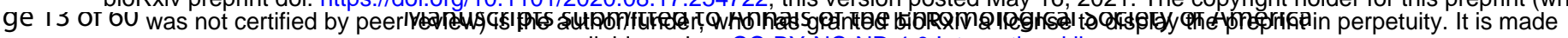
available under aCC-BY-NC-ND 4.0 International license.

examined. Comparing the period length distribution of foragers from our previous temperature cycle experiment with that from the days prior to the phase advance of this experiment revealed significant differences in variance between the experiments (Figure 5D). The fact that the phase

251 advance experiment shows greater variance in period lengths, suggests that many bees were

252 free running and therefore unresponsive to the temperature (Figure 4D and Figure 5A). This

253 period length distribution is similar to the previously observed difference in variance when

254 comparing foragers under constant conditions to those exposed to a temperature cycle (Figure

255 3D). However, although variance was greater it was still significantly less than that under constant 256 conditions $\left(\mathrm{F}_{57,57}=1.83, p=0.0250^{\star}\right)$. Taken together, our results suggest that while $51 \%$ bees 257 responded to temperature and shifted their activity in the direction of the temperature cycle phase 258 shift, $49 \%$ of bees in this experiment did not respond to either of the temperature cycles.

\section{Discussion:}

Here we show that at the periphery of the colony, where foragers spend much of their time

261 (Van Nest et al. 2016), temperature significantly oscillates in a 24 hour period (Figure 1). The

262 amplitude and phase of these oscillations change with respect to the time of the year, and the

263 amplitude varies even less than the environmental temperatures (Figure 2). These findings

264 indicate a tight regulation of temperature oscillations in the periphery of the hive. Simulating this

265 temperature signal in the laboratory is sufficient to synchronize and phase advance the circadian

266 locomotor rhythms of some forager bees, suggesting that temperature could be an important

267 Zeitgeber in the colony (Figure 3, 4, 5). Interestingly, we found that there are large individual

268 differences in the phase of locomotor rhythms with respect to the temperature cycles as well as

269 the responses to a temperature phase shifts. Taken together, we believe that temperature is an

270 important environmental cue inside the colony capable of entraining the circadian rhythms of

271 foragers in nature. 
273 light-dark cycles (Renner 1959, 1960, Moore and Rankin 1985). Recent work has shown that

274 social cues, such as substrate-born vibrations and colony volatiles are capable of entraining and

275 synchronizing the circadian clock of bees (Bloch et al. 2013, Fuchikawa et al. 2016, Siehler and

276 Bloch 2020). However, these experiments do not take into account temperature changes that

277 occur within the colony. Our findings in the present study, as well as those from previous studies

278 (Kronenberg and Heller 1982), suggest that temperature cycles, strong enough to synchronize

279 the circadian rhythms of foragers, are present inside the colony (Figure 1).

The seasonal changes we observed in peripheral temperature (Figure 2), suggest that the 281 active regulation of temperature inside the colony is not limited to the brood nest. This 282 maintenance of the oscillation could serve as a possible entrainment cue for times of the year 283 when bees are unable to go out, such as winter. The delayed phase of the temperature peak 284 during the spring and summer months could potentially play an important role in circadian synchronization for bees inside the colony during their more active periods of the year. Future studies will examine the role of these temperature oscillation in swarming, timing of drone flights and overwintering preparations inside the colony.

291 most strongly to the presence of light, while others concentrated their present locomotor activity

292 during times of overlap between the photophase and higher temperatures (Moore and Rankin 293 1993). Since foragers have been shown to stay inside the colony after visiting their food source

294 (von Buttel-Reepen 1903, Körner 1940, von Frisch 1940, Moore et al. 1989, Seeley 1995), it is 295 possible that, while inside the dark colony, foragers rely on temperature cycles to accurately 296 maintain entrainment to the natural day-night cycle and use light input as a Zeitgeber when 
bioRxiv preprint doi: https://doi.org/10.1101/2020.08.17.254722; this version posted May 16, 2021. The copyright holder for this preprint (which

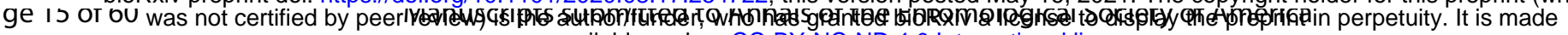
available under aCC-BY-NC-ND 4.0 International license.

297 foraging. This hypothesis stems from the lack of light inside most of the colony (Figure 1). In order 298 to test this hypothesis, further studies exploring the functional role of temperature cycles in the 299 colony as well as the mechanisms of circadian entrainment to temperature cycles are needed. Consistent with the results from the Moore and Rankin (1993) study, we observed that 301 honey bee foragers synchronize to these simulated peripheral temperature cycles. To our 302 knowledge, this is the first time that gradual temperature cycles, simulating those observed in the 303 field, have been utilized in the laboratory. In addition, by simulating the peripheral temperature 304 cycles we found that foragers present a large degree of individual variation in the phase of 305 locomotor rhythms with respect to temperature (Figure 3). Although further studies are needed to 306 understand the functional and evolutionary role of this variation, we can speculate that phase 307 differences of the individual honey bee foragers may result in differences in the temporal 308 allocation of tasks. The individual differences within the foraging population could potentially help 309 with smoothing temperature regulation processes of the colony. This idea is consistent with work 310 where decreasing the genetic diversity of the colony decreases the colonies ability to regulate 311 temperature (Jones et al. 2004, 2007). Another possible functional role for this variation is foraging 312 specialization. This hypothesis would be in line with the results of a recent study that suggests 313 the existence of shift work in honey bees and its genetic component (Bernhard Kraus et al. 2011, 314 Giannoni-Guzmán 2016, Giannoni-Guzmán et al. 2020). Alternatively, the observed differences 315 in the phase of circadian rhythms could be the result of previous entrainment to an outside 316 stimulus, such as light, nectar or pollen. The latter can be evidenced by the ability of foragers to 317 successfully be trained for several days to a food source (Frisch and Aschoff 1987). When performing a 6-hour advance on the temperature cycle, we observed that 319 approximately $51 \%$ individual's locomotor activity advanced and reached stable synchronization 320 with the new temperature cycles, while $49 \%$ were unaffected by either temperature cycle (Figure 321 4). Within individuals unaffected by temperature, we observed a large number of individuals with 
322 short period length. Surprisingly, most of the foragers in this experiment presented short

323 locomotor activity period lengths (Figure 5). This result differs from our previous experiment

324 (Figure 5D) and could be the result of the time of year the experiments took place and that a

325 different colony was used for each experiment. This variation in the change of locomotor activity

326 patterns may reflect differences in the perception of temperature by the circadian system of

327 foragers. Future work could simulate temperature cycles of the higher amplitudes cycles found

328 inside the hive and test bees response to temperature in greater detail

Our results show evidence for temperature entrainment in the form of a strong response

330 to phase advance of temperature by some foragers (Figure 4). Furthermore, given the large

331 degree of individual variation in the free-running period of honey bees and their tendency to

332 present short periods, we interpret the proximity to 24 hour periodicity and the significant decrease

333 in variance as an additional sign of entrainment (Figure 3). Although some individuals gradually

334 shifted their activity after the phase advance, as expected of circadian entrainment, there were

335 individuals that shifted abruptly (Figure 4C). Further experiments to determine whether this

336 particular groups response to temperature represents entrainment or masking are required.

337 Specifically, exposing foragers to temperature cycles and later transferring them into constant

338 conditions would clarify if abrupt responses to phase advance are masking.

Although the mechanisms for light and temperature input to the clock of honey bees

remain to be elucidated, studies in Drosophila have shown that temperature cycles successfully

341 entrain the locomotor and molecular rhythms (Tomioka et al. 1998, Yoshii et al. 2002, Glaser and

342 Stanewsky 2005, Boothroyd et al. 2007). Light and temperature act in a synergistic manner to

343 entrain both locomotor activity and molecular clock of Drosophila (Yoshii et al. 2009). Furthermore,

344 studies indicate that there are clock cells in the brain that selectively respond to temperature

345 cycles, while other clock cells respond to light/dark cycles (as reviewed by Ki et al. 2015). Given

346 the similarities between the neural clock of bees and Drosophila (Fuchikawa et al. 2017, Beer et 
347 al. 2018), it is likely that at least some of the properties uncovered in the fly with respect to the 348 clocks response to temperature will be analogous in the bee circadian clock.

While our results show how temperature variation in honey bee colonies can synchronize

350 the circadian rhythms of foragers, other environmental factors remain to be considered. For

351 instance, we have observed that humidity in the periphery of the colony also oscillates in a 24

352 hour cycle and changes seasonally (unpublished results). In plants it is clear that humidity is 353 capable of entraining the circadian clock (Mwimba et al. 2018). However, whether these 354 oscillations are capable of entraining the clock of bees remains a subject of future research.

355 Taken together, our results indicate that temperature cycles in the colony are capable of 356 synchronizing locomotor rhythms of honey bee foragers. Individual differences in the response to 357 phase advances suggest differences in the sensitivity of the clock to changes in temperature.

358 Future studies will explore the importance of temperature as a time giver in typical colony 359 conditions and its synergistic effects with light and other social cues. Individual differences in the 360 phase of circadian rhythms are loosely reminiscent to those of circadian chronotypes in human 361 populations and with further studies, honey bees could be a potential model for these differences

362 in human populations. Our study adds to the rich and complex interactions of temperature and 363 social organization in honey bees, demonstrating altered temperature effects on circadian 364 rhythms. Research into the functional relevance of this synchronization and the seasonal 365 differences in the colony temperatures may lead to a better understanding of the evolutionary 366 relation of circadian rhythms and sociality.

\section{Acknowledgements:}


371 Manuel Diaz and the personnel of the Gurabo Experimental Agriculture Station of the University

372 of Puerto Rico at Mayaguez for use of facilities at "Casa Amarilla". We would like to thank Josue

373 Rodriguez for his help with data processing. This work was sponsored by the National Science

374 Foundation (NSF) awards 1026560, 1633184, 1707355 and the National Institute of Health (NIH)

375 2R25GM061151-13, P20GM103475.

$376 \quad$ References:

Acevedo-Gonzalez, J. P., A. Galindo-Cardona, A. Avalos, C. W. Whitfield, D. M. Rodriguez,

Beer, K., E. Kolbe, N. B. Kahana, N. Yayon, R. Weiss, P. Menegazzi, G. Bloch, and C. Helfrich-Förster. 2018. Pigment-Dispersing Factor-expressing neurons convey circadian

Beier, W. 1968. Beeinflussung der inneren Uhr der Bienen durch Phasenverschiebung des Licht-Dunkel-Zeitgebers. Z Bienenforsch. 9: 356-378.

Beier, W., and M. Lindauer. 1970. Der Sonnenstand als Zeitgeber für die Biene. Apidologie. 1:

Bernhard Kraus, F., E. Gerecke, and R. F. A. Moritz. 2011. Shift work has a genetic basis in honeybee pollen foragers (Apis mellifera L.). Behav. Genet. 41: 323-328.

Blau, J. 2001. The Drosophila circadian clock: What we know and what we don't know. Semin. Cell Dev. Biol. 12: 287-293.

391 Bloch, G., E. D. Herzog, J. D. Levine, and W. J. Schwartz. 2013. Socially synchronized circadian oscillators. Proc. R. Soc. B Biol. Sci. 280: 20130035-20130035. 
394

395

396

397

398

399

400

401

402

403

404

405

406

407

408

409

410

411

412

413

414

415

416

417

and temperature in the regulation of circadian gene expression in Drosophila. PLoS Genet. 3: 0492-0507.

Buttel-Reepen, H. 1900. Sind die bienen reflexmaschinen?: Experiementelle beiträge zur biologie der honigbiene. Arthur Georgi.

von Buttel-Reepen, H. B. 1903. Die stammesgeschichtliche entstehung des bienenstaates sowie beiträge zur lebensweise der solitären u. sozialen bienen (hummeln, meliponinen, etc.).: Vortrag gehalten auf dem Zoologen-kongress in Giessen (1902). Stark erweitert, mit anmerkungen und zusätz. G. Thieme.

Cheeseman, J. F., E. C. Winnebeck, C. D. Millar, L. S. Kirkland, J. Sleigh, M. Goodwin, M. D. M. Pawley, G. Bloch, K. Lehmann, R. Menzel, and G. R. Warman. 2012. General anesthesia alters time perception by phase shifting the circadian clock. Proc. Natl. Acad. Sci. 109: 7061-7066.

Cyran, S., A. Buchsbaum, K. Reddy, M.-C. Lin, N. R. J. Glossop, P. E. Hardin, M. W. Young, R. V. Storti, and J. Blau. 2003. vrille, Pdp1, and dClock Form a Second Feedback Loop in the Drosophila Circadian Clock. Cell. 112: 329-341.

Detrain, C., J. L. Deneubourg, and J. M. J. M. Pasteels. 1999. Information Processing in Social Insects.

Dunlap, J. C. 1999. Molecular bases for circadian clocks. Cell.

Fahrenholz, L., I. Lamprecht, and B. Schricker. 1989. Thermal investigations of a honey bee colony: thermoregulation of the hive during summer and winter and heat production of members of different bee castes. J. Comp. Physiol. B. 159: 551-560.

Feliciano-Cardona, S., M. A. Döke, J. Aleman, J. L. Agosto-Rivera, C. M. Grozinger, and T. Giray. 2020. Honey Bees in the Tropics Show Winter Bee-Like Longevity in Response to Seasonal Dearth and Brood Reduction. Front. Ecol. Evol. 8: 1-8. 
Forel, A. 1910. Das Sinnesleben der Insekten: eine Sammlung von experimentellen und kritischen Studien über Insektenpsychologie.

Frisch, B., and J. Aschoff. 1987. Circadian rhythms in honeybees: entrainment by feeding cycles. Physiol. Entomol. 12: 41-49.

von Frisch, K. 1940. Die Tänze und das Zeitgedächtnis der Bienen im Widerspruch.

$423 \quad$ Naturwissenschaften. 28: 65-69.

424

425

426

427

428

429

430

von Frisch, K. 1967. The Dance Language and Orientation of Bees. Harvard University Press, Cambridge, MA.

Fuchikawa, T., K. Beer, C. Linke-Winnebeck, R. Ben-David, A. Kotowoy, V. W. K. Tsang, G. R. Warman, E. C. Winnebeck, C. Helfrich-Förster, and G. Bloch. 2017. Neuronal circadian clock protein oscillations are similar in behaviourally rhythmic forager honeybees and in arrhythmic nurses. Open Biol. 7: 170047.

Fuchikawa, T., A. Eban-Rothschild, M. Nagari, Y. Shemesh, and G. Bloch. 2016. Potent social synchronization can override photic entrainment of circadian rhythms. Nat. Commun. 7: 11662 .

Fuchikawa, T., and I. Shimizu. 2007. Effects of temperature on circadian rhythm in the Japanese honeybee, Apis cerana japonica. J. Insect Physiol. 53: 1179-1187.

Galindo-Cardona, A., A. C. Monmany, R. Moreno-Jackson, C. Rivera-Rivera, C. HuertasDones, L. Caicedo-Quiroga, and T. Giray. 2012. Landscape Analysis of Drone Congregation Areas of the Honey Bee, Apis mellifera. J. Insect Sci. 12: 1-15.

Gardner, M. J., K. E. Hubbard, C. T. Hotta, A. N. Dodd, and A. A. Webb. 2006. How plants tell the time. Biochem J. 397: 15-24.

Giannoni-Guzmán, M. A. 2016. Individual Differences in Circadian and Behavioral Rhythms of 
Honey Bee Workers. Dr. Diss. Univerisdad Puerto Rico, Rio Piedras.

442

443

444

445

446

447

448

449

450

451

452

453

454

455

456

457

458

459

460

461

462

463

Giannoni-Guzman, M. A., A. Avalos, J. M. Perez, E. J. O. O. Loperena, M. Kay m, J. A. Medina, S. E. Massey, M. Kence, A. Kence, T. Giray, J. L. Agosto-Rivera, M. A. Giannoni-Guzmán, A. Avalos, J. M. Perez, E. J. O. O. Loperena, M. Kayým, J. A. Medina, S. E. Massey, M. Kence, A. Kence, T. Giray, and J. L. Agosto-Rivera. 2014. Measuring individual locomotor rhythms in honey bees, paper wasps and other similarsized insects. J. Exp. Biol. 217: 1307-1315.

Giannoni-Guzmán, M. A., T. Giray, and J. L. Agosto-Rivera. 2020. Shift work dynamics and division of labor: Honeybee foraging and fanning tasks. bioRxiv.

Giray, T., A. Galindo-Cardona, and D. Oskay. 2007. Octopamine influences honey bee foraging preference. J. Insect Physiol. 53: 691-698.

Glaser, F. T., and R. Stanewsky. 2005. Temperature synchronization of the Drosophila circadian clock. Curr. Biol. 15: 1352-1363.

Heinrich, B. 1980. Mechanisms of body-temperature regulation in honeybees, Apis mellifera: II. Regulation of thoracic temperature at high air temperatures. J. Exp. Biol. 85: 73-87.

Heinrich, B. 1981. The Mechanisms and Energetics of Honeybee Swarm Temperature Regulation. J. Exp. Biol. 91: 25-55.

Heinrich, B. 1993. The Hot-Blooded Insects. 608.

Heinrich, B., and H. Esch. 1994. Thermoregulation in bees. Am. Sci. 82: 164-170.

Himmer, A. 1927. Ein Beitrag zur Kenntnis des Wärmehaushalts im Nestbau sozialer Hautflügler. Z. Vgl. Physiol. 5: 375-389.

Hut, R. A., and D. G. M. Beersma. 2011. Evolution of time-keeping mechanisms: early emergence and adaptation to photoperiod. Philos. Trans. R. Soc. B Biol. Sci. 366: 2141- 
2154.

Jones, J. C., M. R. Myerscough, S. Graham, and B. P. Oldroyd. 2004. Honey bee nest thermoregulation: Diversity promotes stability. Science (80-. ). 305: 402-404.

Jones, J. C., P. Nanork, and B. P. Oldroyd. 2007. The role of genetic diversity in nest cooling in a wild honey bee, Apis florea. J. Comp. Physiol. A Neuroethol. Sensory, Neural, Behav.

Ki, Y., H. Ri, H. Lee, E. Yoo, J. Choe, and C. Lim. 2015. Warming Up Your Tick-Tock:

471 Temperature-Dependent Regulation of Circadian Clocks. Neuroscientist. 21: 503-518. clock. Hum. Mol. Genet. 15.

Körner, I. 1940. Zeitgedächtnis und Alarmierung bei den Bienen. Z. Vgl. Physiol. 27: 445-459.

475

476

Kronenberg, F., and H. C. Heller. 1982. Colonial thermoregulation in honey bees (Apis mellifera). J. Comp. Physiol. B. 148: 65-76.

Levine, J. D., P. Funes, H. B. Dowse, and J. C. Hall. 2002. Signal analysis of behavioral and molecular cycles. BMC Neurosci. 3.

Lindauer, M. 1960. Time-compensated sun orientation in bees. Cold Spring Harb. Symp. Quant. Biol. 25: 371-377.

Moore, D. 2001. Honey bee circadian clocks: behavioral control from individual workers to whole-colony rhythms. J. Insect Physiol. 47: 843-857.

Moore, D., and P. Doherty. 2009. Acquisition of a time-memory in forager honey bees. J. Comp. Physiol. A Neuroethol. Sensory, Neural, Behav. Physiol. 195: 741-751.

Moore, D., and M. A. Rankin. 1983. Diurnal changes in the accuracy of the honeybee foraging rhythm. Biol. Bull. 164: 471-482. 
Moore, D., and M. A. Rankin. 1985. Circadian locomotor rhythms in individual honey bees. Physiol. Entomol. 10: 191-197.

Moore, D., and M. A. Rankin. 1993. Light and Temperature entrainment of a locomotor rhythm in honeybees. Physiol. Entomol. 18: 271-278.

Moore, D., D. Siegfried, R. Wilson, and M. A. Rankin. 1989. The Influence of Time of Day on the Foraging Behavior of the Honeybee, Apis mellifera. J. Biol. Rhythms. 4: 305-325.

Mwimba, M., S. Karapetyan, L. Liu, J. Marqués, E. M. McGinnis, N. E. Buchler, and X. Dong. 2018. Daily humidity oscillation regulates the circadian clock to influence plant

Van Nest, B. N., A. E. Wagner, C. N. Hobbs, and D. Moore. 2016. Dance floor clustering: food-anticipatory behavior in persistent and reticent honey bee foragers. Behav. Ecol.

Panda, S., J. B. Hogenesch, and S. A. Kay. 2002. Circadian rhythms from flies to human.

500 Nature.

Renner, M. 1959. ber ein weiteres Versetzungsexperiment zur Analyse des Zeitsinnes und der Sonnenorientierung der Honigbiene, Zeitschrift F r Vergleichende Physiol.

Renner, M. 1960. The contribution of the honey bee to the study of time-sense and astronomical orientation, pp. 361-367. In Cold Spring Harb. Symp. Quant. Biol. Cold Spring Harbor Laboratory Press. colonies. J. Insect Physiol. 20: 2301-2305.

Seeley, T. D. 1995. The Wisdom of the Hive. Harvard Univ. Press. .... 
Siehler, O., and G. Bloch. 2020. Colony Volatiles and Substrate-borne Vibrations Entrain Colonies. J. Biol. Rhythms. 35: 246-256.

Southwick, E. E. 1985. Allometric relations, metabolism and heart conductance in clusters of honey bees at cool temperatures. J. Comp. Physiol. B. 156: 143-149.

Spangler, H. G. 1972. Daily Activity Rhythms of Individual Worker and Drone Honey Bees1, 2.

Stabentheiner, A., H. PressI, T. Papst, N. Hrassnigg, and K. Crailsheim. 2003. Endothermic heat production in honeybee winter clusters. J. Exp. Biol. 206: 353-358.

Takahashi, J. 1999. Genetic Analysis of Daily Activity in Humans and Mice. 387567.

519 Tautz, J., S. Maier, C. Groh, W. Rossler, A. Brockmann, W. Rössler, A. Brockmann, W.

520 Rossler, A. Brockmann, W. Rössler, and A. Brockmann. 2003. Behavioral performance

521 in adult honey bees is influenced by the temperature experienced during their pupal

522 development. Proc. Natl. Acad. Sci. U. S. A. 100: 7343-7347.

523 Tomioka, K., M. Sakamoto, Y. Harui, N. Matsumoto, and A. Matsumoto. 1998. Light and temperature cooperate to regulate the circadian locomotor rhythm of wild type and period mutants of Drosophila melanogaster. J. Insect Physiol. 44: 587-596.

528 Wahl, O. 1933. Beitrag zur Frage der biologischen Bedeutung des Zeitgedächtnisses der Bienen. Z. Vgl. Physiol. 18: 709-717. 
melanogaster. Zoolog. Sci. 19: 841-850.

533 Yoshii, T., S. Vanin, R. Costa, and C. Helfrich-FÖrster. 2009. Synergic entrainment of

534 drosophila?s circadian clock by light and temperature. J. Biol. Rhythms. 24: 452-464.

Figures and Legends:

537 Figure 1. Temperature oscillates with a 24 hour period in the periphery of the colony. A) Top

538 and side view of a two story honey bee colony presenting the positions of the 5 sensors used to 539 measure environmental temperature and light, inside and outside the hive. Average temperature $540 \pm$ SEM and light environmental data logged at the B) center, C) periphery, D) top, E) entrance and F) 541 outside the colony in the month of October 2013. Temperature was plotted on the left y-axis (black 542 line), while light is plotted on the right $Y$-axis (blue line). As sensors move further away from the center 543 of the colony peak to trough differences $\left(\right.$ Temp $2^{*} \mathrm{~A}$ ) of temperature oscillations increases from $0.7^{\circ} \mathrm{C}$ 544 at the center of the colony up to $16.3^{\circ} \mathrm{C}$ in the top of the colony.

545 Figure 2. Bees actively regulate the phase and amplitude of temperature oscillations in the hive

546 periphery Average temperatures of hive periphery (black) and outside environment across the day in

547 the months of A) May and B) December 2013. Grey and yellow in the background represent the 548 photoperiods during each of these months. C) Mean \pm SEM monthly peak to through Amplitude for 549 the hive periphery and environmental monitors in 2013. Mixed effects model was significant time of 550 year $\left(\mathrm{F}_{(5.31,316.2)}=47.11 ; p<0.0001^{* \star \star *}\right)$ location of sensor $\left(\mathrm{F}_{(11,656)}=10087 ; p<0.0001^{\star \star \star *}\right)$ and their 551 interaction $\left(\mathrm{F}_{(11,656)}=31.56 ; p<0.0001^{* * * *}\right)$. Sidak's multiple comparisons test between groups showed 552 significant differences $\left(p<0.001^{\star * \star}\right)$ for each month with the exception of January and December. D) 553 Mean \pm SEM monthly phase of temperature cycles in the hive periphery (black) and the outside 554 environment (pink). Mixed effects model was significant time of year $\left(F_{(7.369,437.5)}=24.81\right.$; $\left.555 p<0.0001^{* * * *}\right)$ location of sensor $\left(F_{(1,653)}=25.07 p<0.0001^{* * * *}\right)$ and their interaction $\left(F_{(11,653)}=22.55\right.$; 
$\left.556 p<0.0001^{* * * *}\right)$. Sidak's multiple comparisons test between groups showed significant differences

$557\left(p<0.01^{*}\right)$ for marked months.

559 Figure 3. Simulating peripheral temperature oscillations is associated with strong rhythmicity

560 and large individual differences in circadian phase. Representative examples of foragers that

561 presented A) phase advance or B) phase delay with respect to the simulated temperature cycles in

562 controlled laboratory conditions. i) Double plotted actogram of representative individual locomotor

563 activity (blue bars) with simulated temperature overlayed (red lines). ii) Autocorrelation analysis was

564 utilized to determine period length and overall rhythm strength of locomotor rhythms (Levine et al.,

565 2002). iii) Phase of the locomotor rhythms with respect to the temperature cycles $(\psi)$ was quantified

566 using cross-correlation analysis, which compares the distribution of locomotor activity with the

567 temperature cycle and yields the phase as the lag (h). C) Frequency distribution of the phase of

568 locomotor activity with respect to temperature cycle. D) Period length distributions of foragers kept

569 under constant conditions (darkness, $35^{\circ} \mathrm{C}$ ) and bees exposed to the measured peripheral

570 temperature oscillations (t-test: n.s.; $p=0.4641)\left(F_{(57,68)}=7.878, p<0.0001^{* * *}\right)$.

572 Figure 4. Simulated temperature oscillations are capable of phase advancing the locomotor

573 activity of forager bees. Representative double plotted actograms of locomotor activity (blue bars)

574 with simulated temperature cycles overlayed (red lines). At midnight on the $7^{\text {th }}$ day the temperature

575 cycle was advanced 6 hours. For each activity plot the phase of locomotor tor rhythms with respect to

576 the temperature cycles $(\psi)$ was quantified using cross-correlation analysis. Two cross correlations

577 were calculated, the first on days 4,5 and 6 before the temperature manipulation and the second 48

578 hours after temperature change (days 9, 10 and 11). A) Representative plot of forager synchronizing

579 his locomotor activity rhythm to the phase of temperature in response to temperature advance. B)

580 Representative individual maintaining a consistent phase relationship with simulated temperature

581 cycles before and after the temperature manipulation. C) Representative plot of forager showing an 
582 abrupt response to temperature advance. D) Representative forager showing no response to 583 temperature advance.

\section{Figure 5. Relationship of phase changes and period length of locomotor activity A)}

585 Representative double plotted actogram of forager presenting short activity period length and no 586 apparent response to temperature cycle manipulation. Cross correlation analysis for days 4,5 and 6 587 before the temperature manipulation and days 9,10 and 11 are shown with respect to the temperature 588 cycle during these days. B) Correlation examining the relationship between the magnitude of phase 589 change and the phase before the temperature advance resulted in a significant correlation (Pearson $\left.590 r(58)=-0.3282, p=0.012^{*}\right)$. Magnitude of the phase change was calculated as follows: ((Phase after 591 temperature advance - Phase before temperature advance)/6) x100. C) Correlation of the Magnitude 592 of the phase change and the period length of the locomotor activity before the temperature advance

593 (Pearson $\left.r(58)=-0.3411, p=0.009^{* *}\right)$ D) Period length distributions of foragers kept exposed to 594 temperature cycles from our first experiment and days 4-6 before the environmental manipulation of 595 phase advance experiment (t-test: n.s.; $p=0.0592)\left(F_{(57,68)}=4.31, p<0.0001^{* * * *}\right)$. 


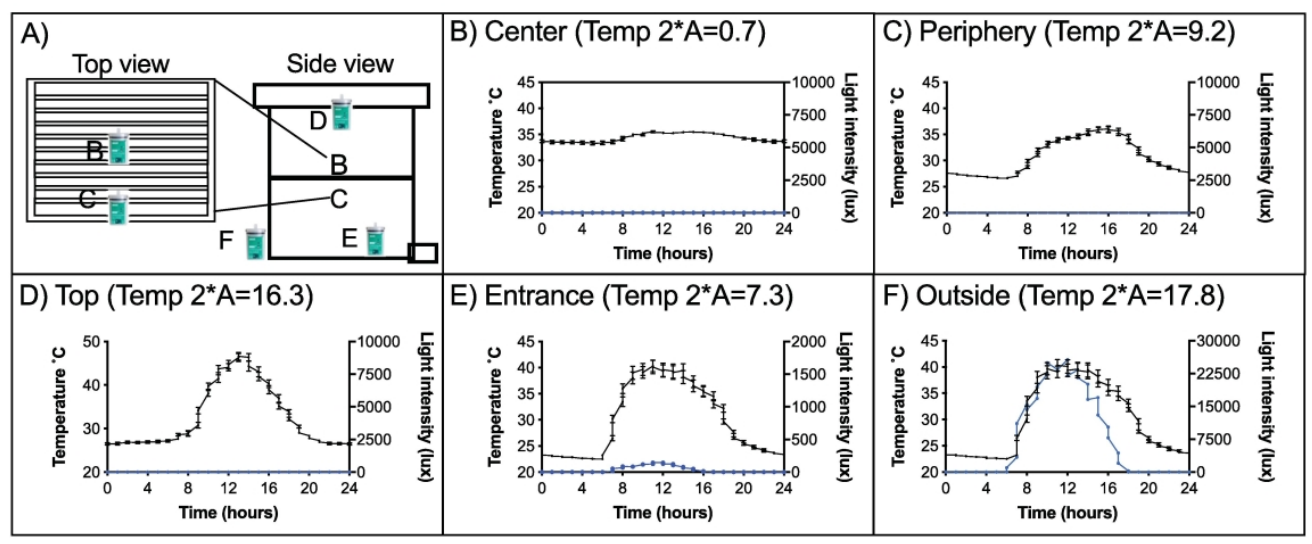

Figure 1

$194 \times 80 \mathrm{~mm}(600 \times 600 \mathrm{DPI})$ 
A) May 2013

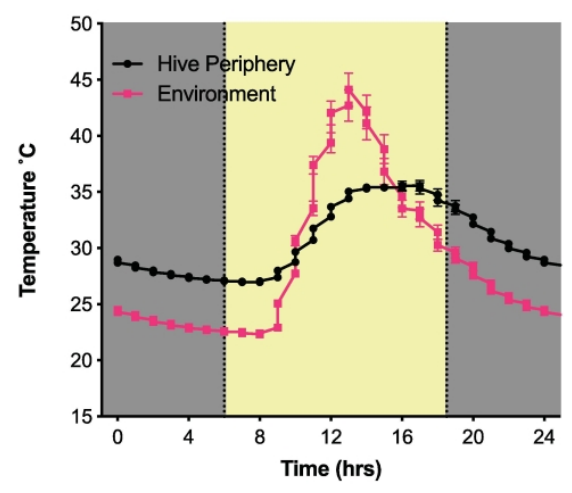

B) December 2013

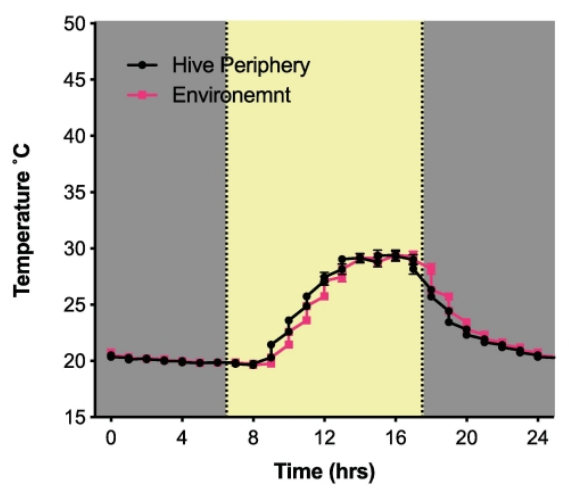

C) Mean Monthly peak to trough Amplitude in 2013

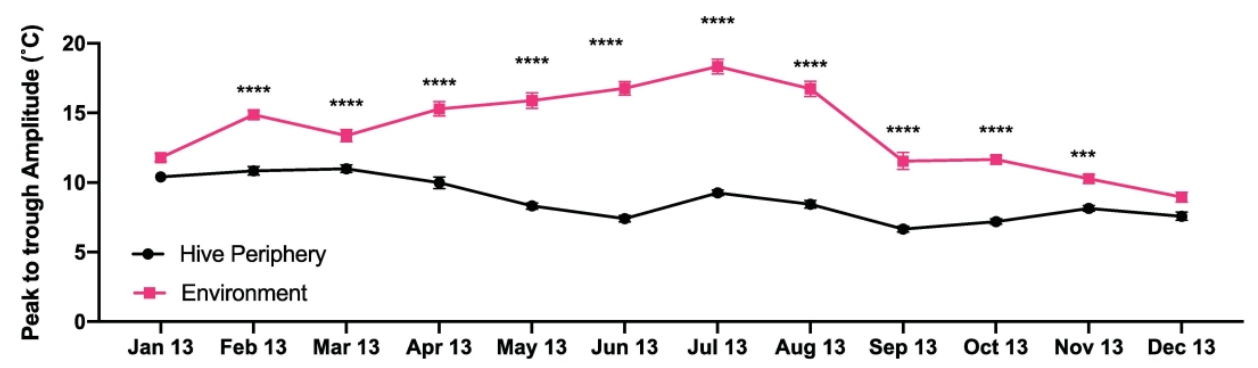

D) Mean Monthly Phase of Temperature cycles in 2013

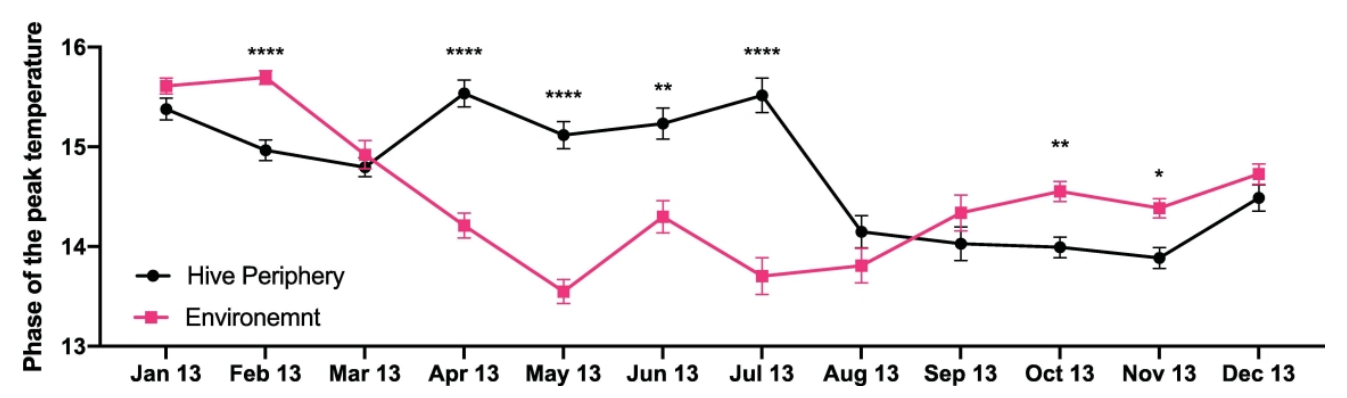

Figure 2

$195 \times 230 \mathrm{~mm}(600 \times 600 \mathrm{DPI})$ 


\section{A) Advanced forager}
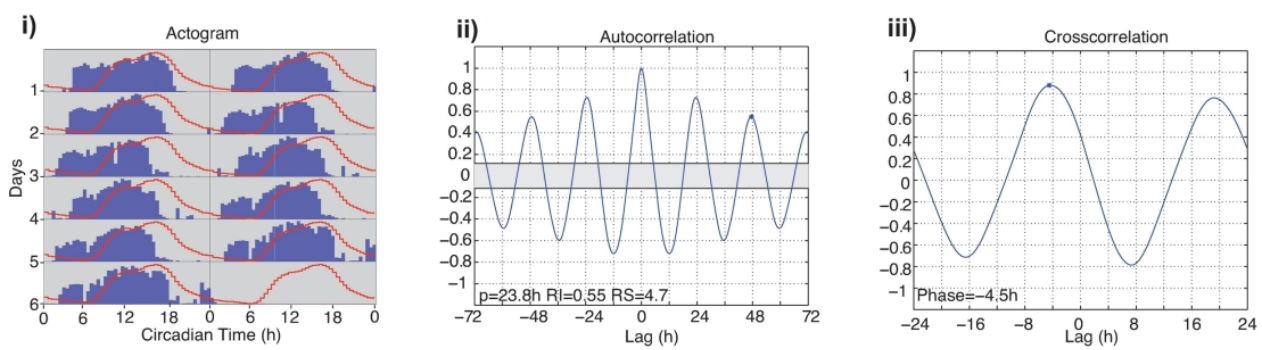

\section{B) Delayed forager}

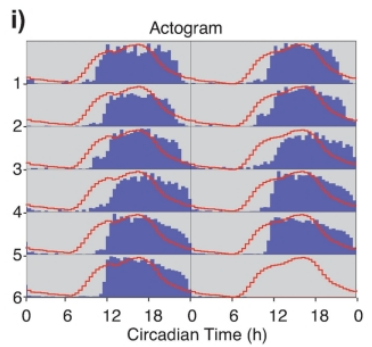

C) Phase Distribution

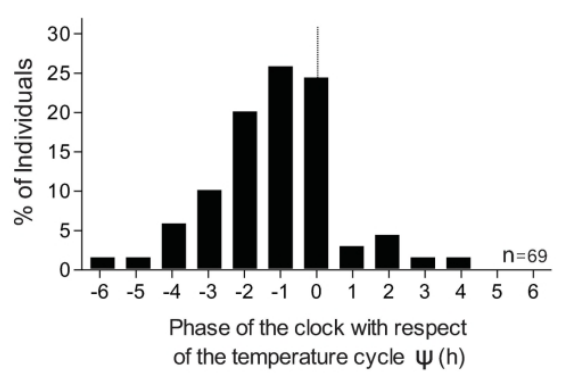

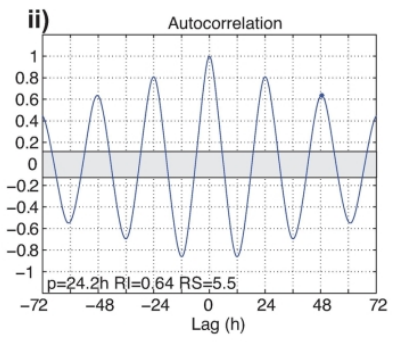

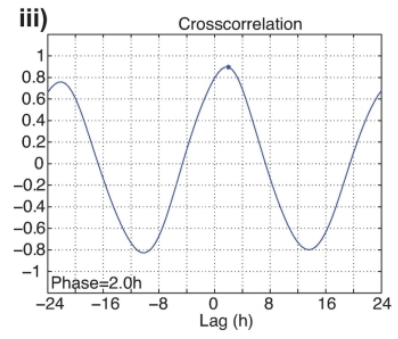

D) Period length Distribution

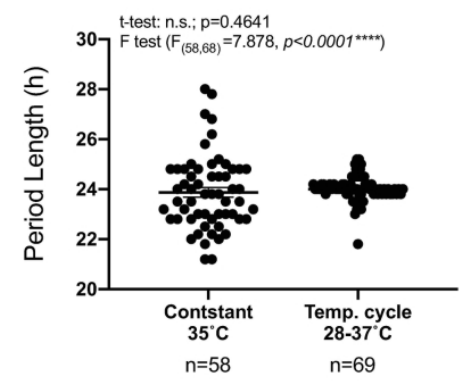

Figure 3

$215 \times 231 \mathrm{~mm}(300 \times 300 \mathrm{DPI})$ 
bioRxiv preprint doi: https://doi.org/10.1101/2020.08.17.254722; this version posted May 16, 2021. The copyright holder for this preprint (which

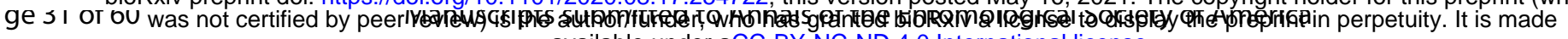
available under aCC-BY-NC-ND 4.0 International license.

A) Forager shifting his activity with temperature advance

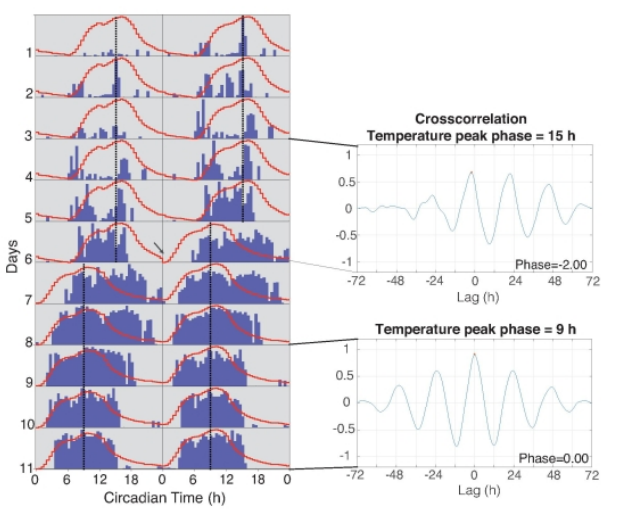

C) Forager presenting abrupt response to temperature advance

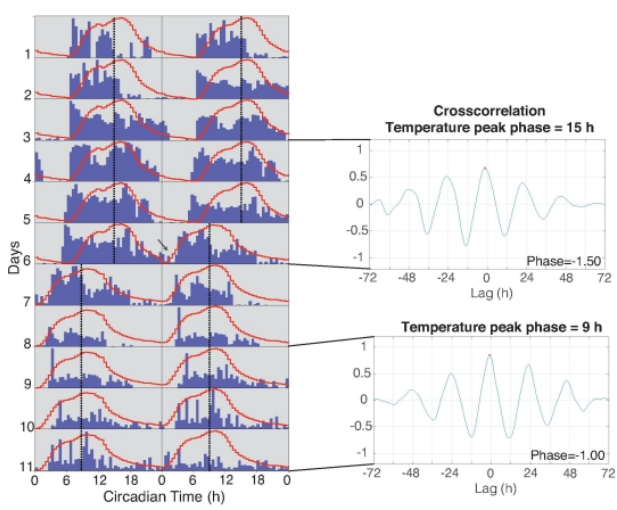

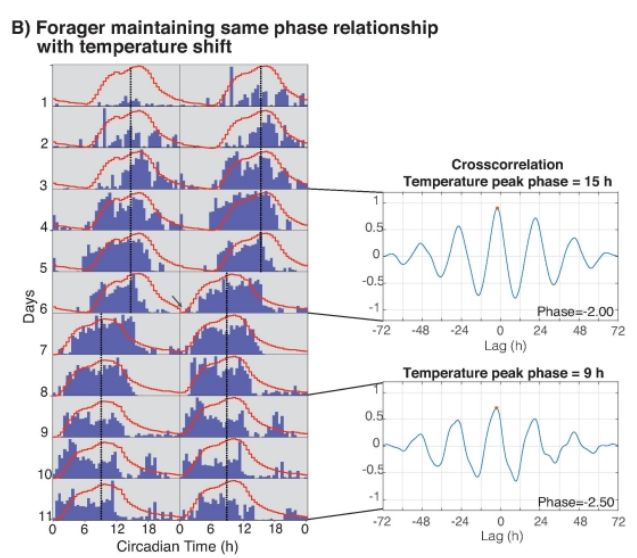

D) Forager lacking a response to temperature advance

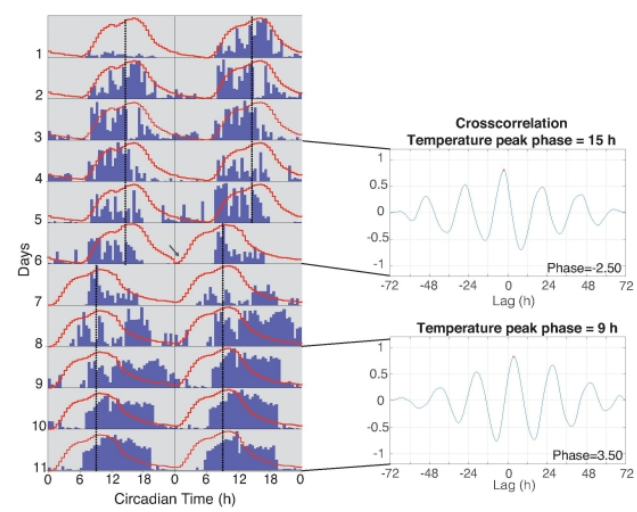

Figure 4

$170 \times 147 \mathrm{~mm}(600 \times 600 \mathrm{DPI})$ 

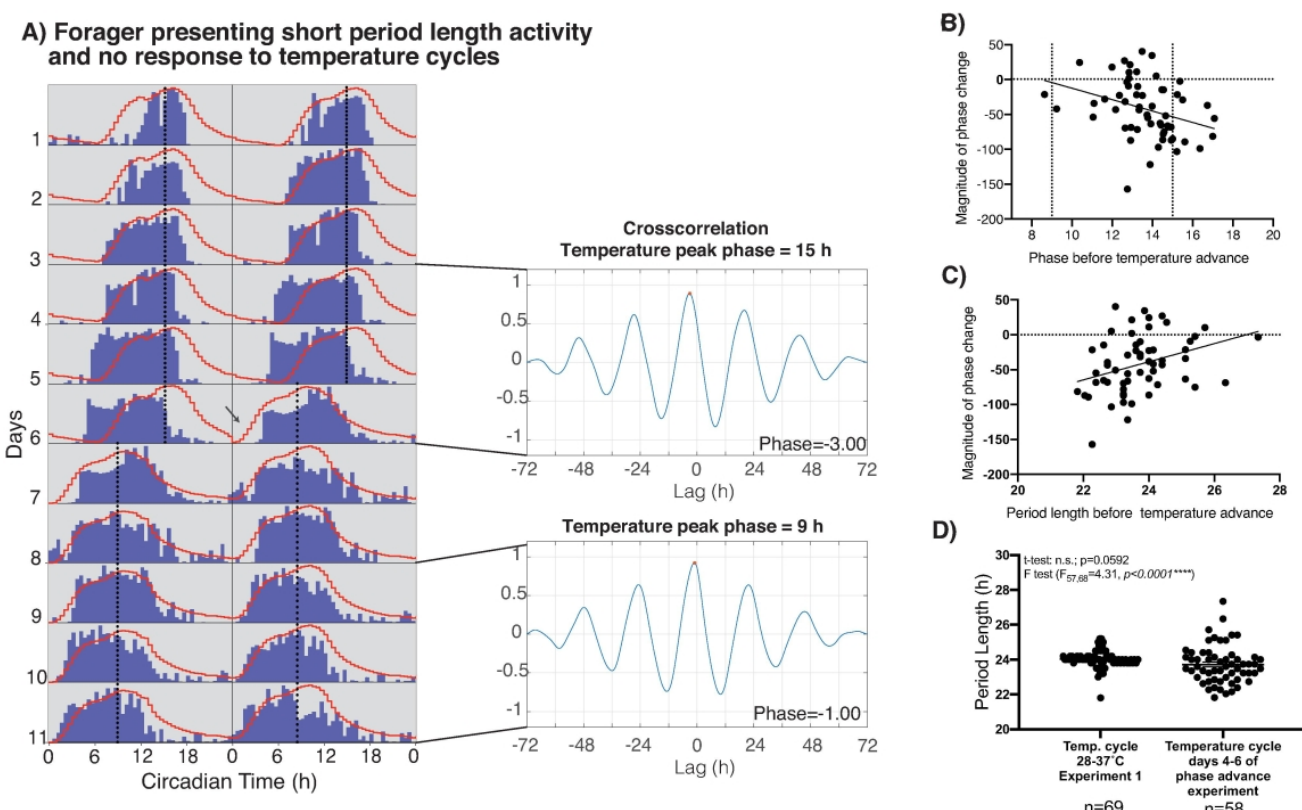

\section{C)}

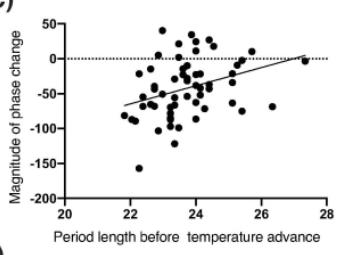

D)

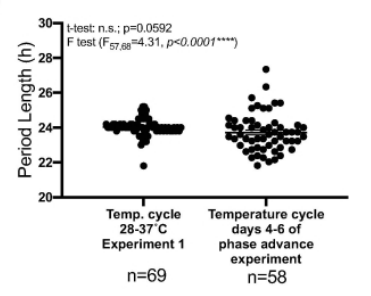

Figure 5

$170 \times 105 \mathrm{~mm}(600 \times 600 \mathrm{DPI})$ 